\title{
Rehabilitating existing high-rise residential buildings: the idea of Ecoskin
}

\author{
E. Kalisch Rotem \\ Faculty of Architecture and Town Planning, \\ Technion - Israel Institute of Technology, Israel
}

\begin{abstract}
This paper presents the idea of Ecoskin: an additional ecological layer that enfolds fragments of housing surfaces in existing high-rise dwelling buildings. This added new coat is independent, detached from the existing building both conceptually and structurally. It can supplement all typical houses built with $20^{\text {th }}$ century technologies, and enable their ecological recuperation.

Ecoskin emerges from the conflicts of modern living within the natural environment: striving to raise the quality-of-life, to enable energy savings and to filter external environmental damages and yet enable buildings to tackle their own self-created hazards. It collects runoffs, accumulates solar energy, recycles grey water, allows for better insulation, ameliorates the air quality, and even designates spaces for private businesses and agriculture.

Ecoskin also deals with the ecology of communal life, confronting two major problems created by the rigidity of modern land-use: the lack of vivid street life (as often created at the footsteps of high-rise residential buildings); and the inability to cater for alternative lifestyles, for which the combining of living, working and recreation is a necessity. While dealing with these issues, Ecoskin aspires to revive and reclaim the public realm.

This paper will attempt to demonstrate how a simple and inexpensive structure that coats existing residential high-rises can potentially improve the connection of people to their natural environment as well as to their social surroundings, and yet, revive the public realm around high-rise residential areas.

Keywords: vertical green architecture, high-rise, residential buildings, ecological skin, ecological coat, transformation, improvement, existing buildings.
\end{abstract}




\section{Introduction}

This paper presents the idea of Ecoskin - an additional ecological layer that enfolds parts of housing surfaces in high-rise residential buildings. This additional new coat is independent, detached from the existing building, both conceptually and structurally, suitable for all typical houses built using $20^{\text {th }}$ century technology in Israel and worldwide, thus enabling their recovery and health.

The future of our plant is largely dependant upon the built environment. One of its prime issues is not only how to tackle future developments, but rather how to deal with what already exists. From our perspective, the fate of housing lies not only in a gaze into the future, but also, in facing and confronting the past.

The conceptual project presented in this paper, done in collaboration with architect Ari Nashiv, has been submitted to an Israeli architectural competition for ideas "building green high-rises", initiated by The Israeli Ministry of Environmental Protection and the Israeli Architect's Society (June 2007). The proposal received "a special award for the improvement of existing urban fabrics", a category that was generated by a jury's decision post factum, in order to emphasize its conceptual contribution. It was later displayed in a group exhibition at the House of Architects in Jaffa, Tel-Aviv, in October 2007, and in the WATEC conference exhibition in Tel-Aviv, in November 2007.

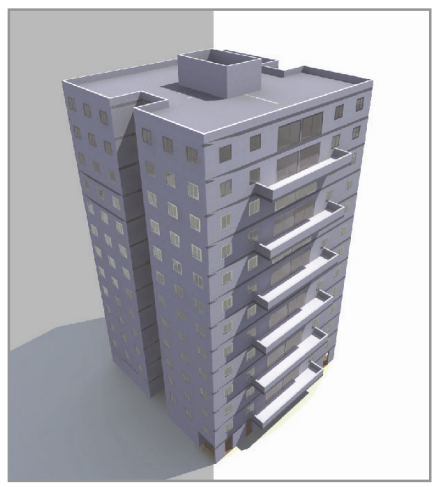

Figure 1: The object of Ecoskin: existing high rise residential buildings.

The design of Ecoskin attempts to avoid any affiliation with architectural vogues or trends. This project introduces a concept, a solution and a method which can and should be subjected to manifold morphological expressions, depending on the contexts, the creators, and the prevailing design conventions. Design-wise, the bare presentation of Ecoskin is meant to emphasize the conceptual as well as the ideational, hoping not to draw excess attention to what we believe to be peripheral at this stage. This idea can thus develop in many ways. 

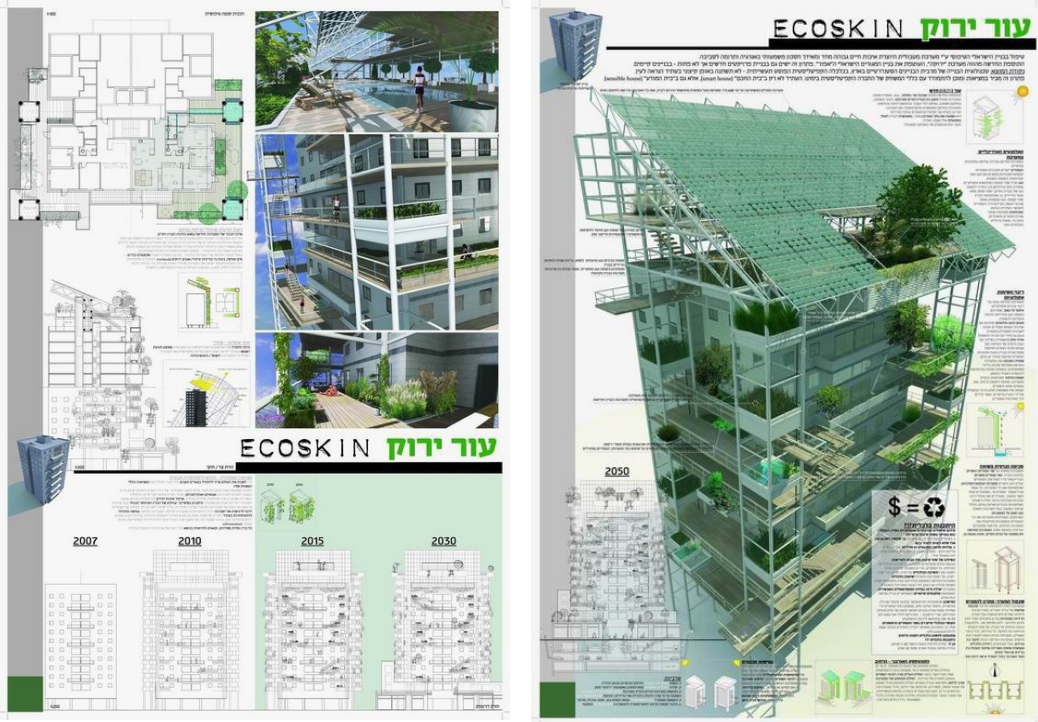

Figure 2: The proposal for the architectural competition of ideas, June 2007.

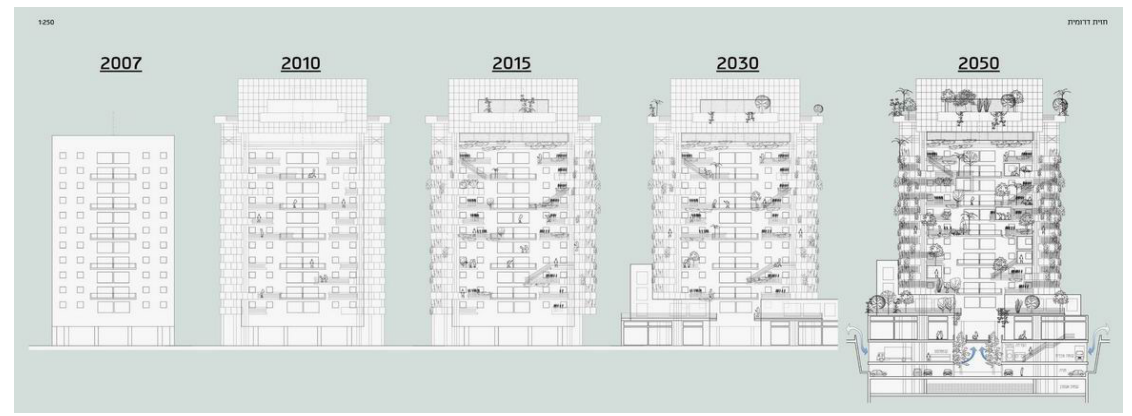

Figure 3: Adaptability and pliability - a flexible concept and implementation.

Ecoskin's basic premise is that the current building technology is not likely to change significantly in the near future, within capitalistic circumstances. This solution acknowledges economic and social conditions, and is ready to face the game-rules of contemporary post-industrial, western societies. The system is based on a simple and inexpensive structure (made of either cement or steel), with prefabricated elements, that enable buildings to develop gradually. It strives to become a flexible artifact, subjected to diversified future scenarios. However, flexibility lies not only in the methods of construction, but also in the level of adaptability, based on the belief that in order to change the world - one must advance in small steps. While some high-rise tenants may want to participate in such a project in order to improve their real-estate values and gain balconies, others may opt to add sophisticated metabolic systems derived from their high awareness to the environmental situation. 
Between reality and utopia - every person should be able to deal with the ecological issue in one's own way and according to one's own pace. We believe that a small improvement is always better than stagnation, as we can no longer afford to remain oblivious.

\section{A balanced ecological system}

Ecoskin applies to two distinct conceptual strata: the relationship of high-rise dwellers with their natural environment; and the relation of high-rise dwellers to their social environment, communal life and the urban public realm.

\subsection{Formulating the concept: the tectonics of Ecoskin}

Ecoskin functions as a balanced live metabolic system that carries multifarious roles: hoping to raise the quality-of-life and to enable energy savings, it attempts to filter external environmental damages and yet enable buildings to tackle their own self-created hazards.

\subsubsection{An independent structural artefact}

The new Ecoskin system is structurally independent, not being supported by the existing building. The structural solution is mostly suitable for existing projects, but can also apply to new ones as well. The new added system accommodates itself to diverse situations - reacting to the earth and sun's directions as well as to urban conditions.

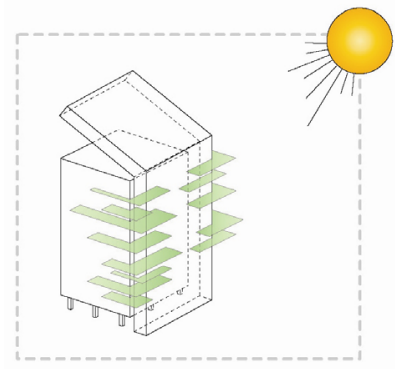

Figure 4: An independent artefact.

\subsubsection{Numerous compositions}

The direction of the building as per landscape or scenery does not always go in tandem with the sun path position. In the Israeli situation, this type of ecological skin would be most efficient turning to the southern hemisphere, whether southeast or south-west, which is not necessarily the optimal direction to posit a highrise buildings (e.g. in Haifa, the most impressive view of sea and harbour is directed to the north). Ecoskin is most efficient when posited at the front or main façade of the hgh-rise building, although it provides many benefits when posited around its other sides as well. 


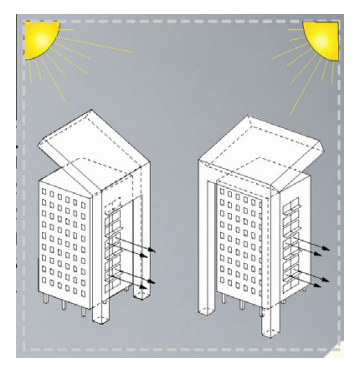

Figure 5: Numerous compositions.

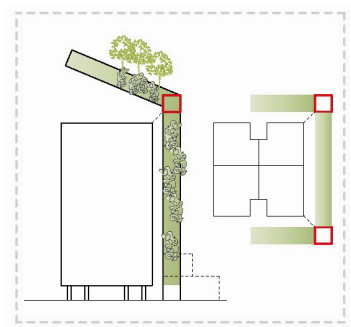

Figure 6: The role of corners.

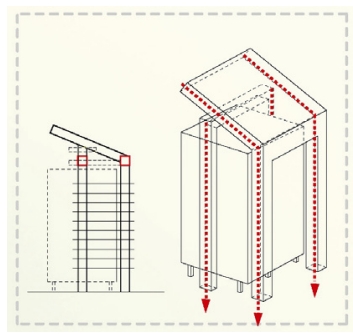

Figure 7: The structural scheme.

\subsubsection{The preeminence of the building corners}

The main structural elements, the pillars, are posited at the corners of the building in order to avoid obstructions or any blockage of view from within the apartment units. In most high-rise buildings, the corners are unutilized dead spots. Large pillars supporting the weight and expanse of ecological systems (soil, water etc), will not interrupt the inhabitants, and will even turn underused spaces to be significant.

\subsubsection{The structural scheme}

the system consists of two structural frames, standing each on two solid pillars. Each pillar is composed of several columns. The front frame of the truss supports the roof, which also leans on the central frame of the truss. The front 


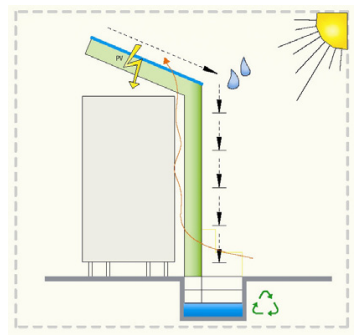

Figure 8: Multifarious ecological roles.

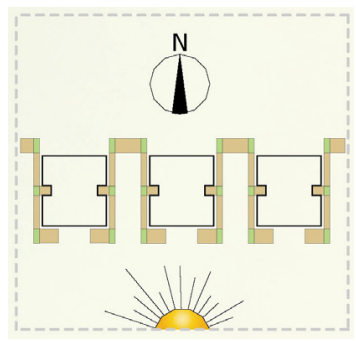

Figure 9: $\quad$ Solution for mass society.

and the central parts separate the two water systems: runoffs (descending through the front pillars into the wetlands and planter units) and grey water (collected from the buildings bathrooms and laundry rooms) into the central pillars.

\subsubsection{Multifarious ecological roles}

Ncoskin collects runoffs and solar energy, recycles grey water, allows for better insulation, ameliorates the air quality, and even allows for the designation of spaces for private businesses and agriculture, usages as further elaborated.

\subsubsection{Solution for the mass society}

This additional layer can turn any high-rise building to be ecologically sensible, regardless of its location or position. Entire neighbourhoods can dress-up with a green coat and change not only their appearance, but also their way of living.

\subsubsection{A pliant and gradually growing solution}

Ecoskin may evolve as per building inhabitants, their extent of awareness and willingness to invest in the new system and in the new lifestyle it inheres. We believe that along the development of such projects, the enthusiasm and willingness of the inhabitants to cooperate and contribute will only grow, due to the better environment and improved surroundings that will provide them with a substantial source of identification and pride [1].

\subsection{Healing the natural environment}

In order to fathom the contribution of Ecoskin to the building's natural ecology, the following points must be set forth. 


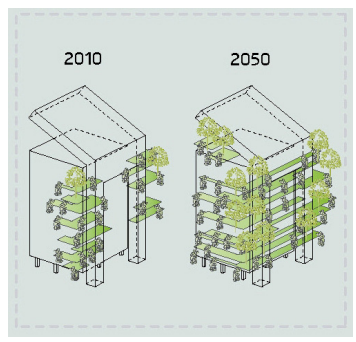

Figure 10: Flexible, pliant and gradual solution.

\subsubsection{Hydrologic system and water efficiency}

The roof collects surface runoffs, leading water flows through balconies and gardens until reaching an underground reservoir. Grey water is collected from the apartments, distributed to pools and wetlands that serve for urban agriculture. Water is assembled at the structural corners, as these can deal with its significant load.

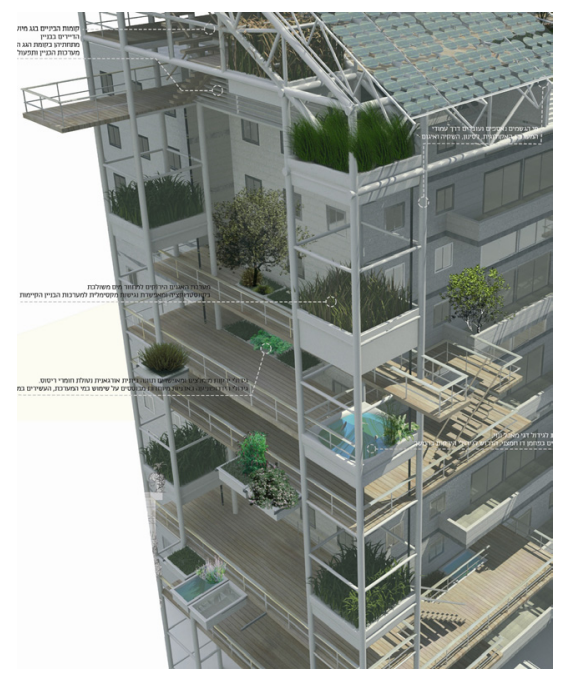

Figure 11: Water treatment.

\subsubsection{Wetlands}

the structural reinforced pillars are capable of holding significant load: water ecology, aquatic plants, phyto-technologies and biological systems can find a location inside these pillars, which consist of a considerable footage to treat wastewater, and to grow plants capable of reducing levels of pollutants.

\subsubsection{Energy consumption}

The roof is comprised of photovoltaic cells that allow the penetration of light into the upper floor [2]. The new upper floors can serve as the building's public 
space, designated for recreation or urban agriculture. Air pockets are formed between the new Ecoskin system and the existing building, creating an aperture that filters the impact of external thermal conditions on the building's temperature. The greenery that covers the new system not only offers a significant insulating layer but also absorbs $\mathrm{CO}_{2}$, thus contributing to better air quality.

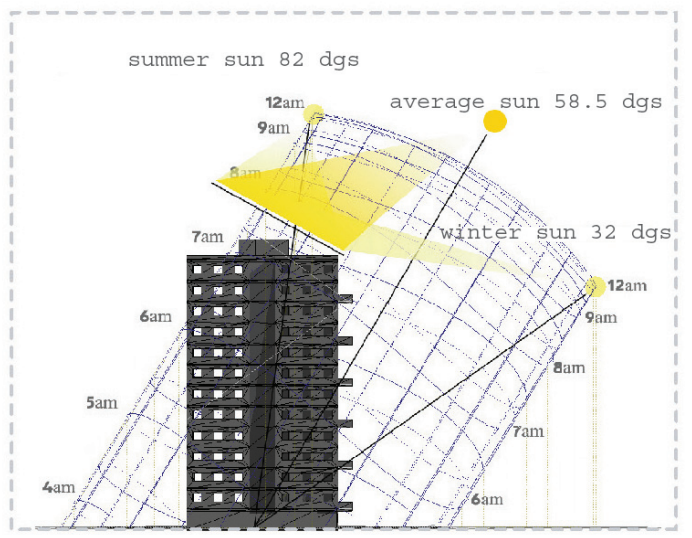

Figure 12: Energy consumption.

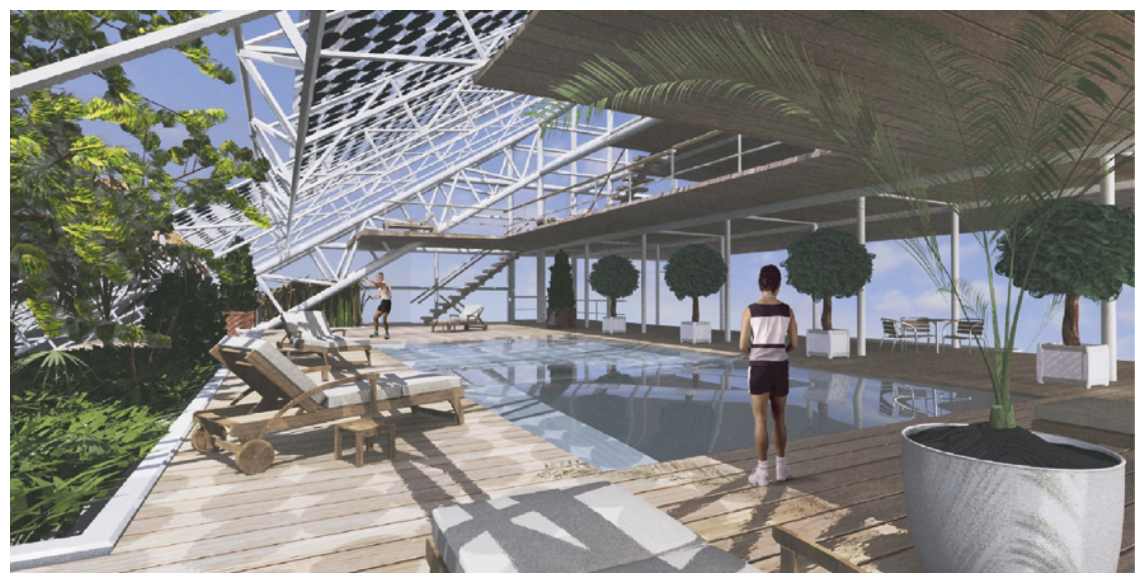

Figure 13: The roof floor, designated for inhabitant's public use, catering for recreational needs and intensive permaculture.

\subsubsection{Recycling}

An entire floor is designated for recycling, located at the foundation of the new system beneath the pillar level at the building's entrance. Waste descends through the system's structure, channeled into the technical space where waste collection and separation takes place. 


\subsubsection{Greenery and private agricultural production}

Broad gardening areas will control the solar heat gain of the building [3], and may facilitate the creation of urban agricultural soils, for private use or for local vendors. Hydroponic cultivations can be nourished from the system's water, which is rich with minerals. Home cultivation of organic vegetation will become common and simple.

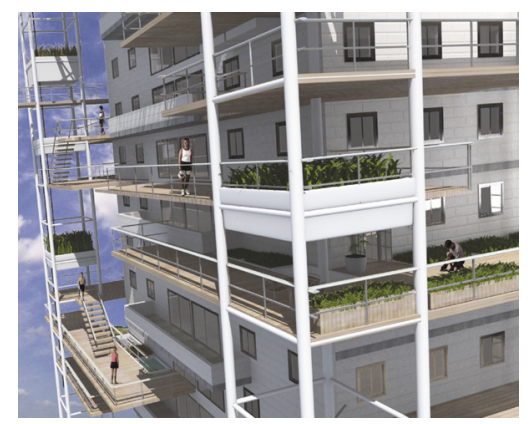

Figure 14: Terraces with greenery.

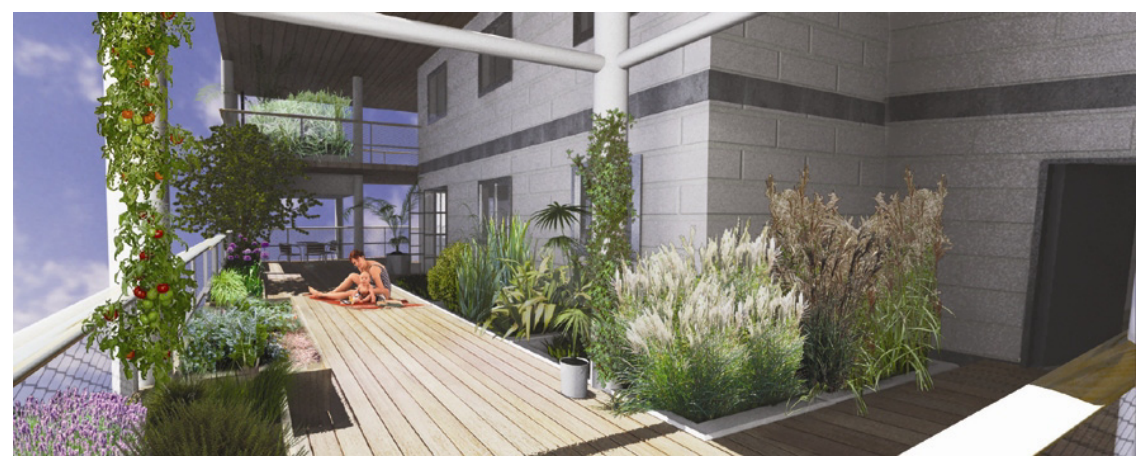

Figure 15: Home organic vegetation and hydroponic cultivations.

\subsection{Healing the social environment}

Ecoskin faces up to the ecology of communal life as well, confronting two major problems created by the rigidity of modern land-use: the lack of vivid street life as often created at the footsteps of high-rises; and the inability of residential environments to cater for alternative lifestyles, for which the combination of living, working and recreation is a necessity. Confronting these two issues, Ecoskin aspires to offer a refreshing surroundings for diversified inhabitants. The more diverse people are, the more effect they bear on the vividness and vigor of the public realm [4]. Thus, by altering the land use on ground level, Ecoskin aspires to revive and reclaim the public realm 


\subsubsection{Reacting to context}

The lower part of the ecological system, which is adjacent to the street level, reacts to the immediate urban surroundings, disassociated from the upper floors of the system which pertain to the ecological conditions of the building (e.g. sun paths). In other words, Ecoskin comprises of two disparate sub-systems each oriented towards a different direction, or affected by a different factor: the main upper part, and the lower ground part. The existing building is naturally determined by the urban context; the upper main part follows its spherical conditions and sun-path positions; and the lower part on the ground is influenced by the urban street context. Combinations of these sub-systems respond to the particular situation, and can therefore end with rich and diversified solutions.

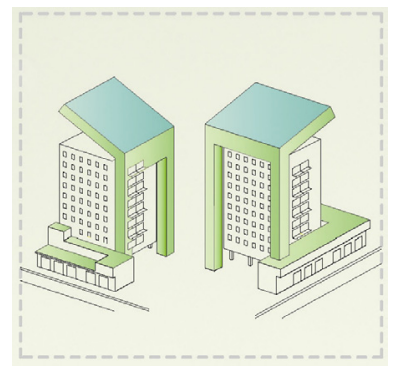

Figure 16: Reacting to urban context on the street level.

\subsubsection{Changing the layout of the public realm}

high-rise buildings, especially those built during mid and late $20^{\text {th }}$ century, normally stand on ground floor pilotis, forming the building's entrance space, which is often associated with negative characteristics such as placelessness [5] and lack of proprietors. Ecoskin proposes a new use to the ground level, and to the next couple of floors above. Beneath the new structure, as also inside the pilotis - spaces can be allocated for commercial or business usages and face the street. The first and second floors can offer additional enclosed spaces annexed to the apartment units of the building, accessible from the street as well. All these spaces can be used as working spaces (small offices, studios, shops, workshops etc.), enabling several units in the building to enjoy both worlds: living and working. The foundations of the new structure can be dug further in, and allow car access into underground spaces (or parking lots) beneath the building. The rest of spaces, standing at the foot of the pillars, are designated for recycling activities - storage and treatment.

\subsubsection{Alternative lifestyles}

high-rise residential buildings are often the settings of nucleus families. The building's apartments tend to accommodate inhabitants from similar backgrounds and socio-economic classes. There is reason to believe that several units combining living function with spaces for working activities may instigate heterogeneity instead of homogeneity, pluralism instead of totality [6], and herald the advent of new lifestyles. 


\subsection{Ideological foundations}

Between utopia and reality, theoretical thinking has a tendency to remain detached from daily life, or to lose its depth, breadth and power as it approaches the everyday. Referring to the ecological crises and to its recognition arising in the last couple of decades, these two worlds - theory and practice - must find ways to be bridged rather urgently. Green architecture theoretical thinking is growing richer and vaster, but precedents remain few and little in proportion to the growth of the crisis.

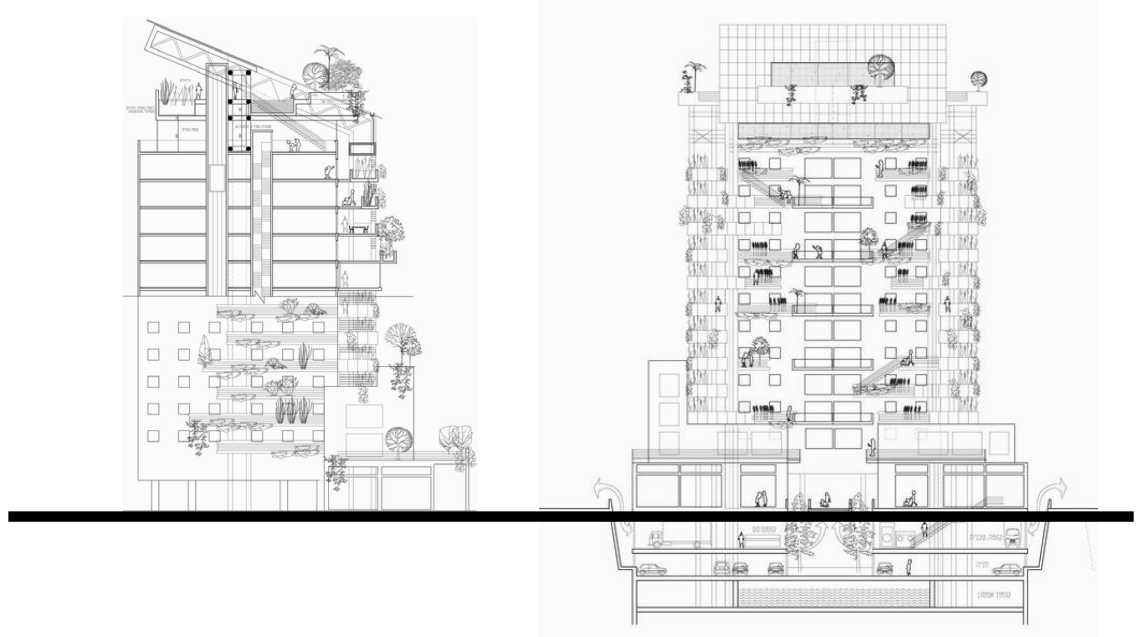

Figure 17: Elevations/sections intertwined: the impact of the system's foundations on the street level.

The ecological problem emerged in its vast extent due to modern demands and lifestyles of urban mass society, western and non-western[7]. Consequently, mass society is where solutions must be sought after. Mass society is where green architecture must happen; and feasible economy is the key to make it happen.

Green architecture seems to appeal so far to the elite society. Moreover, it appears to be mostly applicable in the architecture of upper socio-economical classes. The future of green architecture must find ways to penetrate lower socioeconomical classes, middle and working, and thus leave its imprint on the mass society.

Green architecture combines architectural considerations with cutting edge technologies in an inextricable way. Such technologies may herald the rectification of future building industry, but might also remain inaccessible and inapproachable due to their costliness. Fathoming technological innovations is not only mandatory but also crucial; however, if one wants to direct the building industry unto a different current, then one must deem feasibility as a pivotal 
factor. The future lies in the simple and in the popular, because these are the things that truly affect our daily reality.

Ecoskin integrates theoretical ideas into a practical and inexpensive solution, which can be widespread not only geographically but between all economical classes as well. It attempts to accumulate a diversified range of greenarchitectural knowledge, most of which is rather simple and ordinary, and fuse it into one multi-task structure. It may be assumed therefore that Ecoskin can apply to the mass society, and as such, has the capability to bring forth a new urban reality.

\section{Conclusions}

Ecoskin is an additional ecological layer that enfolds parts of housing surfaces in high-rise residential buildings. This independent new coat is detached from the existing building both conceptually and structurally, pertaining to all typical houses built using $20^{\text {th }}$ century technology in Israel and worldwide, thus enabling their recovery and health.

This paper attempted to demonstrate how Ecoskin functions as a balanced live metabolic system, carrying multifarious roles: raising the quality of life and enabling energy savings, it attempts to filter external environmental damages and yet enables buildings to tackle their own self created hazards. Ecoskin also deals with the ecology of communal life, confronting major problems created by the rigidity of modern land use: the lack of vivid street life and the inability to cater for alternative lifestyles. Dealing with these issues, Ecoskin aspires to revive and reclaim the public realm.

This paper aims to demonstrate how a simple and inexpensive structure, coating existing residential high-rise buildings, can improve the connection of people to their natural physical environment as well as to their social surroundings, and yet contribute to the amelioration of the public realm in various residential areas.

\section{References}

[1] Logan J.R. \& Molotch H.L. (1987), Urban Fortunes - The Political Economy of Place, University of California Press, LA, p. 107

[2] This roof is designed as an intensive eco-roof system, since there is adequate load-bearing capacity, see Kibert C.J, (2005), Sustainable Construction Green Building Design and Delivery, Wiley: New Jersey, pp. 154-156

[3] Greenery as part of the role of building envelopes, see also in Kibert C.J, (2005), Sustainable Construction - Green Building Design and Delivery, Wiley: New Jersey, p. 194

[4] Florida Richard (2002), The Rise of The Creative Class, and how it's Transforming Work, Leisure, Community and Everyday Life, Basic Books, pp. 223-229

[5] Relph E (1976), Place and Placelessness, London: Pion

[6] Ellin N. (1996), Post Modern Urbanism, Blackwell Publishers, p. 123

[7] Rogers R. (1997), Cities for a Small Planet, Westview Press, pp. 4-5 